\section{OPERATIONAL RESEARCH IN WAR AND PEACE}

A

DISCUSSION on operational research in war and peace was held by the Division of the Social and International Relations of Science of the British Association, during the Dundee meeting of the Association. The chair was taken by Dr. C. H. Desch and the discussion opened by Sir Robert Watson-Watt. Other speakers included Dr. O. H. Wansbrough-Jones, Prof. S. Zuckerman, Prof. W. C. Wilson, Prof. F. A. E. Crew, Mr. L. Moss and Prof. J. D. Bernal.

Sir Robert Watson-Watt said he believed that responsibility for the term 'operational research' rested with himself. He had no recollection of any positive definition, which did not emerge until late in the work, although it contained something of "doing arithmetic for Air Staff", market and consumer research, and the less naively offensive elements of motion study. Neither did he recognize the description of operational research by the president of the British Association, Sir Henry Dale, as that "which estimated destructive effects and planned destructive policy". If terms of reference were needed, he would suggest these, for industry as well as in war :

"To examine quantitatively whether the user organisation is getting from the operation of its equipment the best attainable contribution to its overall objective, what are the predominant factors governing the results attained, what changes in equipment or method can be reasonably expected to improve these results at a minimal cost in effort and time, and the degree to which variations in the tactical objectives are likely to contribute to a more economical and timely attainment of the overall strategic objective."

Operational research, Sir Robert proceeded, is beginning to look very like real scientific management, and he believes that it is an important contribution to the still unsolved problem of the relationship between the administrator and the expert. The essence of that licensed busybody, the operational researcher, is that he has learnt about things and about people, that he "lisps in numbers, for the numbers come", and that he is believed by the individual user of technical equipment because he and his like have been shown capable of ensuring great improvements in the performance of the equipment and in the comfort, security and selffulfilment of the user. In war, the pioneer practice in the R.A.F. might be described as having been centrifugal, certainly as highly devolutionary, and the naval counterpart was by contrast highly centralized. In peace, Sir Henry Dale had a right to ask whether "we can accept as directly obvious the suggestion that Operational Research . . . would qualify for guidance in the immeasurably more complicated and fundamentally different problems of reconstruction". It would be disastrous if this legitimate query were misread and misapplied as a positive statement of rejection. Sir Robert doubted whether the peace ensemble is, in fact, more complex than the war ensemble, nor could he perceive any fundamental difference between the problems within a peace-time industry and those on one side of the gulf of war. The argument, he considered, was "desperately important" and he said he meant every syllable and stress of those words.

In conclusion, it was with profound regret that he had heard Sir Henry Dale speak of the "conscription of science". All that was asked by those who believed in the present application of operational research, and felt that "the rocks might crumble beneath the ivory city", was that they "be given the academic freedom of operational research to measure the facts, the dangers and the towering possibilities".

Dr. O. H. Wansbrough-Jones, speaking of Army applications, stated that the method should have improved on that recommended by Newton for navigational technique by the introduction of better statistical and other scientific tools; and on current methods of administrative planning in the Army by giving greater freedom both in opportunities of direct observation and of freedom from daily routine. Also, although successes might rightly be claimed by those who did the work, their scientific training and objective approach would have been insufficient if there had not been a readiness, especially at high levels, to receive, absorb and encourage these scientific men and to heed their results ; if there had not been a few outstanding men of science to lead the work, as well as a sufficient body with a good knowledge of the ways, tasks, and difficulties of the Army; and, pervading it all, the intense stimulus of national need. Unless each condition was met, at least in part, this type of work would not be useful.

Home sections were formed during the War to study tank gunnery, field artillery and infantry weapons, and the process culminated in the provision of a further six sections to work in theatres of operations. Up to the end of 1945 , some 365 scientific workers were employed in operational research on behalf of the army, the maximum number employed at any one time being about 174. Up to date, they had produced some 380 reports of varying importance roughly equivalent in size to the average scientific paper, and nearly 600 memoranda of smaller importance, besides dealing with a very large number of day-to-day queries. Those at home had worked under the Ministry of Supply, and the overseas sections under indirect War Office control. The present scientific force is very much reduced, and the division between the Ministry of Supply and the War Office still remains, but the relationship is very close and likely to become closer.

Taking two overseas sections as examples, that with 2lst Army Group had a maximum strength of twelve. It was in the theatre of operations from D-Day until July 1945, and produced some forty reports covering a variety of subjects most of which had been suggested by the investigators themselves. Those first selected, after a few weeks of initial study, were the location of enemy mortars, the distribution of hits and penetrations in our own and the enemy's tank casualties, the performance and best method of use of the PIAT, the problem of dust on roads and airstrips, and the examination of mud. Of these, that on dust was taken over by the Air Force, that on mud proved too valuable, and the PIAT work was mainly technical; but the mortar location and tank casualty work was completed with good results. The report on the first was the factual basis of the counter-mortar organisation later set up with 21 st Army Group : that on the second provided accurate data on how armour should be distributed on tanks fighting in close country. Work was also continued on the two basic problems of air and artillery bom. bardment, and events led the operational researchers back to them. Among the results was the first objective assessment of the effects achieved by a given weight of bombing in support of ground troops. 
The corresponding section with the 14th Army in Burma determined maintenance tonnages and man-power wastage. In the event, the application of these two studies to the planned assault on Malaya and Singapore remained untested. As to the need in such work for highly trained scientific workers, Dr. Wansbrough-Jones suggested that, although operational research probably did not demand such training, it was greatly helped by scientific training. "It is much more", he stated, "than the straightforward collection of facts and the writing of histories ; it must continually seek out new sources of information, especially the least obvious, and by sound reasoning from the facts, provide a new understanding of its particular problem." In peace the emphasis falls naturally on training and administration, and it is hoped to study, in particular, the adequacy of the existing motive of Army service, means for increasing its value, and the effectiveness of substitute motives such as group or individual rewards, the acquisition of knowledge and skills, and the use made of synthetic trainers of various types.

Dr. Wansbrough-Jones believes that for some young scientific men, those really interested in the social applications of science, diversion for a time to operational research, but not for too long, would be not only justifiable but desirable. With adequate safeguards, and good career control, it would be an advantage to many to work for a year or so, say in their late twenties, for a Government department; to leave industrial laboratories to work on the scientific man-power sides of their industries, and defence laboratories to work with the Services. Army plans for the last are being put into force.

Prof. S. Zuckerman distinguished between operational research at the technical, tactical and strategic levels. At the first level was an investigation of the manner in which bombs cause casualties, and it was at this level that the better part of the scientific man-power engaged with the Fighting Services during the War was employed. Operational research into different kinds of tactics and methods of organisation consumed the bulk of the remaining effort. One example was the relationship between different types of formation-flying and accuracy of bombing. Scientific men, with their understanding of the techniques involved, appreciation of the tactical problems to be overcome, and emphasis on objectivity and statistical method, can arrive at solutions about tactics which could have been derived only accidentally by other methods. Scientific intervention at the level where major strategic policy is determined was slight-although it would have been impossible for the Ministries of Food and Home Security, for example, to take reasonable decisions on policy without the constant help of expert knowledge, fortified in one case by nutritional surveys and in the other by a large organisation working experimentally and in the field. On the military plane, however, most major operational policy was determined without recourse to scientific advice, and examples of scientific intervention are thus few. Lord Cherwell, as Paymaster-General and scientific adviser to the Prime Minister, was no doubt able to bring scientific method to bear on decisions affecting major policy. In addition, two specific examples were quoted. In the anti-U-boat campaign, scientific analysis not only helped to determine the convoy system, but also assisted in showing the value of diverting four-engined bomber aircraft to U-boat patrols. The second concerned the strategic policy underlying the employment of heavy bombers against the enemy. Objective and quantitative analysis showed that the bomber offensive against German industrial cities was not depressing the level of German production to the extent hoped for, but that attacks against communications would have a far-reaching and immediate effect. Revision of strategic policy in the spring of 1944 was based on this objective appreciation, which was confirmed by subsequent examination in Germany.

What was true about the value of scientific method during the War is no less true to-day, Prof. Zuckerman proceeded. War is not a state of unfettered individual enterprise, any more than unfettered individual enterprise could be the characteristic of the present economic and political state of Britain or Western Europe as a whole. The Government has added to the normal function of administration executive duties which make it necessary either that officials should lean more and more upon scientific advice or become more and more scientific themselves. Cabinet planning bodies such as that presided over by Sir Guy Plowden, and the Advisory Council on Scientific Policy presided over by Sir Henry Tizard, may be regarded as operational research sections established at a strategic level in the economic field. As the situation develops, the function of such different bodies may find a common meeting-ground for the exposition of the major economic, scientific and administrative problems which have to be taken into consideration in a fruitful peace-time strategy.

Prof. W. C. Wilson described the work of No. 1 Medical Research Section in the Middle East between May 1942 and April 1943. Its mandate covered all matters concerning the welfare of fighting men in a very large territory with several distinct and varied climates. The reports of Dr. A. L. Chute, a Canadian physician and physiologist, gave extensive factual data on wounds, evacuation of wounded, fatigue, effects of stress, hours of sleep, food, appetite, cooking and other aspects of tank fighting. Dr. E. T. C. Spooner, a Cambridge bacteriologist, undertook a general survey of Middle East conditions, and studied the typhus situation in Egypt, desert sores, and the outbreak of infective hepatitis of late 1942. Prof. Wilson's own work was on the problems of burns and 'wound shock'. Points which stood out in retrospect were the value of a section cornposed of independent, full-time and fully mobile observers; and the conclusion that minority opinions should not be ignored, even when counter to expected results. The shortage of trained medical investigators had proved a handicap, and Prof. Wilson was not optimistic that it could be easily or quickly remedied. But if the latent forces of interest and idealism in the medical profession could be mobilized, they might provide a research weapon of immense power in new fields such as social medicine.

Prof. F. A. E. Crew discerned two phases in the application of scientific research in a protracted war : the first in which the production of machines and materialities were the essential preoccupation, and the second in which these were gradually overtopped by problems of the health, morale and efficiency of men. It had been expected that the Army Council would refer to the Medical Research Council any problem of urgency and military importance which fell into the sphere of the biological sciences; but this arrangement did not work, and Sir Edward Mellanby had ultimately created a field investigational organisation which provided the model, so far as he 
knew, for what was later done by the Army itself. Lessons for the future were that the nature, and even the existenee, of a problem of quite serious importance could remain unrecognized until investigated by selected and highly trained scientific workers; that mixed teams are required, of compositions determined by the probable nature of the problem; that hopeful investigation depends on willingness on the part of the community to participate actively; that results, however potentially valuable, can remain disregarded until thoroughly appreciated at the topmost levels; and that for rapid solutions, simultaneous investigation in different circumstances by different teams is a very great advantage. The only danger is that, with the return of peace, the Medical Research Council might find it necessary to withdraw from social biology.

Mr. Louis Moss, director of the Government Social Survey, referred to the need for studies of both the social and industrial conditions of particular jobs, as well as of the attitudes of potential recruits, if labour were to be induced rather than compelled to particular industries.

Prof. J. D. Bernal, as the last speaker, was handicapped by the length of discussion which had already taken place, and what follows is based on the written contribution which he had intended to make. The same needs, he contended, that led to the appearance of operational research in war should now lead to the conversion of that experience to peaceful uses, since the gap between imports and exports and the impossibility of Britain feeding itself are at least as serious and immediate as any war situation. 'Operation Production' should be considered with the same urgency and common purpose as 'Operation Overlord'. The technique of operational research could be made available to find out what has to be done, to check the success of the operation and modify its conduct. It is essential that the country's very limited resources in trained man-power in engineering and science should be used in the most effective way with a scientifically determined system of priorities, weighing not only present resources, but also those which could be increased, often by very large factors, by the application of high-pressure research and development. Only a combination of economists, engineers and scientists could achieve this; but they must operate on the highest planning authority in the country. The most obvious priorities are coal, steel, building and agriculture, but others such as transport, distribution and the utilization of chemical wastes may prove equally important. Prof. Blackett's general principle of operational research should be used, to do those things which combine the greatest need with the most rapid possibility of achievement.

All these are in the nature of economic planning, but physical research is required wherever materials and techniques have to be transferred from their present use to some new one. Lively and effective research would also be necessary on the workshop and farm level, and all the ingenuity in the country would be needed to solve the thousand small problems that would arise. Thousands of scientific workers and engineers are being used in a wasteful manner or for purposes of secondary importance-a very large number in industry and probably as many in Service research. Operational research is needed to find the bost distribution and to check redistribution. It would be tragic, he concluded, if this one organisational development of the War were not given the chance to show its capacity in the peace.

\section{THE INSTITUTE OF SEAWEED RESEARCH}

"TERE, Scotland has a chance. Eire, Norway, America, Japan, have all, in varying ways, exploited their soaweed resources. We are only at the beginning, and this splendid research station gives us the opportunity not only of making up on these countries, but of surpassing them." So declared the Right Hon. Joseph Westwood, Secretary of State for Scotland, when, on September 19, he officially opened the headquarters of the Scottish Seaweed Research Association-the Institute of Seaweed Research, Inveresk Gate, Musselburgh, Midlothian. Until recently a large mansion house, Inveresk Gate now contains adequate botanical, chemical, engineering and photographic laboratories, engineering workshops, a drawing office, a library, and conforence and display rooms, apart from the necessary offices. The Institute stands in eleven acres of ground, and is situated sufficiently near Edinburgh, the University, and the sea to meet the Association's various needs.

The Association was formed in June 1944, and until Inveresk Gate became available the director and staff used the King's Buildings (of the University of Edinburgh) A.R.P. Control Centre as offices, as well as certain of the University's research laboratories and facilities. During the first two years of its life the Association was financed by moans of a grant of $£ 25,000$ from the Development Fund. Thus was made possible a survey of Scottish seaweed resources and investigations into methods of harvesting, handling and processing these resources. Now, Government has provided over a period of five years a further sum of $£ 90,000$, and it is hoped that at least another $£ 10,000$ will be forthcoming from industry, and from public-spirited individuals.

Dr. F. N. Woodward is director of the Institute, but at the moment has been seconded to act as director of the United Kingdom Scientific Mission in the British Commonwealth Scientific Office in Washington. The acting director is Major P. Jackson. Under this joint direction the staff of the Institute operates under three divisions: botanical, chemical and engineering. The activities of these divisions may be outlined, as in the director's report, as follows :

(1) Survey of Scottish seaweed resources. (a) De. velopment of reliable survey methods. (b) Quantitative survey of the Scottish coast for littoral, sublittoral and cast brown weeds. (c) Study of economic and ecological factors. (d) Determination of optimum conditions of growth by controlled culture.

(2) Harvesting and processing investigations. (a) Development of economic harvesting methods. (b) Determination of optimum conditions of drying, grinding and processing.

(3) New and extended uses of seaweed and seaweed products. (a) Determination of the chemical composition of Scottish seaweeds and its variation with change of species, season, age, environment, etc. (b) Determination of the properties and characteristics of the chemical components of seaweed and their derivatives, with the view of finding new and extended uses. (c) Development of methods of pro. duction of such constituents and their derivatives as are of potential technical value. (d) Determina. tion of the value of seaweed as a component of animal feeding-stuffs and as a fertilizer. 